\title{
Destino cor-de-rosa, tensão e escolhas: os significados do casamento em uma capital amazônica (Belém, 1870-1920)*
}

\author{
Cristina Donza Cancela ${ }^{* *}$
}

\begin{abstract}
Resumo
Este artigo procura discutir as práticas e representações em torno do casamento a partir da trajetória de mulheres $e$ homens pertencentes a distintos segmentos sociais, que viveram em Belém durante o período de expansão da economia da borracha. Para tanto, foram consultados inventários, processos civis e criminais, matérias de periódicos e fontes eclesiásticas.
\end{abstract}

Palavras-chave: Casamento, Família, Amazônia.

* Recebido para publicação em março de 2007, aceito em novembro de 2007.

** Doutora em História pela Universidade de São Paulo, professora do Departamento de Antropologia da UFPA e membro do Grupo de Estudos de Gênero "Eneida de Morais". donza@ufpa.br

cadernos pagu (30), janeiro-junho de 2008:301-328. 
Destino cor-de-rosa, tensão e escolhas

A Rosy Fate, Tension and Choices: The Meanings of Marriage in an Amazonian Capital City (Belém, 1870-1920)

\begin{abstract}
This article discusses practices and representations of marriage through the lives of women and men from various social classes who lived in Belém during the Rubber Boom Era. Research targeted inventories, civil and criminal suits, newspaper articles and religious sources.
\end{abstract}

Key Words: Marriage, Family, Amazon. 
Para além de um preceito normativo e a formação de uma nova unidade conjugal, o casamento pode ter múltiplos significados para as mulheres de diferentes grupos sociais, alterando papéis sociais, formas de identificação e expectativas de vida.

Qual o significado do casamento para pessoas pertencentes à elite $e$ aos segmentos populares? Que proximidades $e$ especificidades podemos encontrar na vivência e no valor dado ao casamento por pessoas com distintas situações sociais? Será que podemos falar de casamento formal em meio a pessoas pobres?

Para pensar estas e outras questões visitamos algumas histórias de mulheres que viveram em Belém, no final do século XIX e início do século XX, em plena expansão da economia da borracha.

\section{Miss Felicidade e outras histórias}

Começaremos destacando a narrativa autobiográfica da escritora Eneida Costa, que usava o codinome Miss Felicidade ao escrever para a Revista A Semana. Ao falar da trajetória dela e de três amigas, em uma de suas inúmeras crônicas, Eneida deixa claro de que forma o casamento representou um rito de passagem em suas existências, uma mudança de status social e de vivência.

Miss Felicidade inicia afirmando que as quatro amigas se conheceram no navio que as levara ao Rio de Janeiro, onde iam passar um tempo - prática que parecia comum às jovens ricas da época que buscavam formação, ilustração e conhecimento de costumes ditos modernos e civilizados na então capital federal. Ao retornar, o grupo formado por Rennée Chermont, Hilda Vasconcelos, Marina (de quem não se sabe o sobrenome) e a própria Eneida organizava eventos sociais, alguns deles beneficentes, como o festival em prol da Cruz Vermelha Brasileira, por conta da primeira guerra mundial que então acontecia nos campos europeus. E assim seguiam elas, segundo Eneida: 
Destino cor-de-rosa, tensão e escolhas

Vivendo sempre a trocar idéias e livros, sempre alegres, cheias dessa alegria santa da mocidade; até que a primeira de todas casou - Hilda Vasconcellos. Depois Yayasinha embarcou também para o Rio. Agora Renée se casou e partiu. Levamo-la a bordo e voltamos com olhos vermelhos de chorar: e com ella partiu um muito de nosso coração. Ella partiu feliz porque realizou seus sonhos de ventura. Levou-a pelo braço aquelle que ella distinguiu entre todos para tornal-o seu marido (...) E o nosso grupo esta a desfazer-se. Hilda em São Paulo; yayazinha no Rio e Renée em Manaus. Estamos a separar-nos lentamente. Felizmente porém, todas marchamos para dias felizes e para um futuro cor-de-rosa (A Semana, 08.05.1918).

Se para a escritora o casamento se revestia de um destino feliz e cor-de-rosa, ele igualmente significava perda e mudança, não apenas de status social, mas também de lugar, de relações de amizade e lembranças.

Renée Chermont, a última das amigas a casar-se, era filha de Antonio Leite Chermont, agente da Companhia de Comércio e correspondente do Jornal do Commercio, no Rio de Janeiro, além de diretor e proprietário do Jornal Estado do Pará. Filha de uma tradicional família de pecuaristas da ilha do Marajó, os Chermont, ela se casou com um acadêmico de Direito e funcionário público em Manaus, Cícero Costa.

Seus esponsais foram anunciados nos jornais locais, cerca de um ano antes do enlace matrimonial, como acontecia em meio às famílias abastadas. A mesma divulgação teve a cerimônia de casamento, onde se lia:

\section{Enlace Costa-Chermont}

Realiza-se no dia 19 em Belém, o enlace matrimonial do estimável moço Cícero Costa, residente em Manaus, com a distincta mademoiselle Renée Chermont, filha do Dr. Antonio Chermont, director-proprietario do "Estado do Pará". Figuras das mais distinctas do set belemense, os jovens noivos gosam das mais merecidas sympathias na 
nossa sociedade, constituindo por isso esse casamento, um verdadeiro acontecimento social em nosso meio...

(A Semana, 17.04.1920).

Menos de um mês após a cerimônia religiosa e civil de seu casamento, Renée embarcou para a capital do Amazonas, onde o marido residia, como outras amigas suas já haviam feito. Eneida, sua amiga escritora, foi a única que se formou, tendo cursado a faculdade de Odontologia existente em Belém. ${ }^{1}$

Os fragmentos da trajetória de vida dessas quatro jovens amigas permitem que se conheça mais de perto o universo em que estava envolta a prática do casamento e seu significado para essas mulheres da elite local.

Nas palavras de Eneida, "é o fato que marca o fim de uma mocidade", e, com isso, a mudança de status e uma nova sociabilidade, por vezes, em outra cidade, seguida de uma residência neolocal pela linhagem do marido, afinal: "Renée foi para Manaus, Yayazinha para o Rio...". Desse modo, o casamento implicou na quebra de laços de amizade juvenis e o início de novos papéis sociais.

Importantes trabalhos já demonstraram que no casamento entre membros da elite prevalecem as uniões legítimas e os arranjos matrimoniais pautados na tentativa de equilibrar os interesses familiares à expectativa dos pares, levando em conta a manutenção e a ampliação do patrimônio, bem como a tradição, a influência e o prestígio social e político da rede de parentesco (Samara,1989; Nazzari, 2001). Nesse sentido, o enlace matrimonial é algo que envolve não apenas os contraentes, mas também suas famílias, sendo o ritual do casamento objeto de divulgação $e$ expressão da condição social das mesmas.

Não era à toa que, quando anunciada uma união nas manchetes dos periódicos que circularam em Belém, era o nome de família que vinha preferencialmente citado, em detrimento dos

1 Até onde se pode seguir as notícias da Revista A Semana, no ano de 1921, não foi encontrada referência ao fato de Eneida Costa ter se casado. 
Destino cor-de-rosa, tensão e escolhas

noivos que iam efetivar o matrimônio, como pôde ser observado anteriormente no anúncio de casamento de Renée Chermont e Cícero Costa publicado na revista A Semana. Nesse mesmo periódico, em seção correspondente aos fatos ocorridos na sociedade - batizados, casamentos e festas - encontravam-se manchetes como:

Enlace Pereira-Sodré Gomes.

...O jovem casal Maria de Lourdes Pereira Gomes e Lauro Sodré Gomes, cujo consorcio se effectuou recentemente nessa capital. A noiva é neta do coronel Juvêncio Sarmento, influente político no Pinheiro e o noivo, filho do major José Olympio Gomes (A Semana, 09.1919).

Da mesma forma, as cerimônias eram detalhadamente descritas em matérias de jornais e revistas. No casamento ocorrido em 1902 entre Consuelo Alvarez e o advogado Liberato de Castro, oriundos de duas famílias de comerciantes, toda a cerimônia civil realizada na vivenda do pai da noiva - comendador Hilário Alvarez -, e a cerimônia religiosa realizada na Catedral da Sé foram minuciosamente descritas. As ruas do trajeto que levavam ao palacete do pai do noivo, Dr. Liberato de Castro, onde se realizou a recepção, foram uma a uma citadas. Ambas as residências localizavam-se na Estrada de "Nazareth", espaço de morada de muitas das famílias da elite local. Diz a matéria que, logo após a cerimônia civil, "um rozário de carros desfilou pela estrada de Nazareth rumo ao Largo da Sé..." (Botelho, 1973:74).

O nome de família das pessoas que participaram da cerimônia de casamento foi igualmente citado, bem como as roupas das mulheres descritas detalhadamente. Até mesmo o programa do concerto musical tocado na cerimônia ganhou destaque nas matérias. O requinte coube à exposição das jóias que o noivo ofereceu à noiva, realizada na casa comercial Villa \& Gonzáles, para visitação e conhecimento público. 
A exposição, a ostentação e a divulgação aqui destacadas revelam para a sociedade a riqueza das famílias envolvidas, o seu pertencimento, evidenciando sua distinção e a construção de um espaço social diferenciado, uma hierarquia bem demarcada, o bom gosto e o dom de que fala Bourdieu (1973:66). Mais do que o enlace em si, a maneira de realizá-lo era expressão de condição social e prestígio. Como dizia a matéria, "entre os convivas porém, do que Belém possue de bello e mais aristocrático" (Botelho, 1973:68). Dessa forma, as distinções de fato eram transformadas em distinções significantes, ainda lembrando as proposições de Bourdieu.

Entretanto, embora os valores e práticas socialmente tidos como legítimos estejam mais próximos da vivência e da representação de pessoas pertencentes aos grupos de elite, não necessariamente elas são uniformemente vividas e incorporadas, mesmo pelas pessoas desses segmentos. Muitas vezes, as expectativas e arranjos familiares entram em conflito com opções individuais.

Foi assim com o casamento de Maria de Nazareth Ferreira Gomes de Miranda, filha do Capitão Antonio Gomes Corrêa de Miranda, grande proprietário de terra e criador de gado na vila de Cachoeira, ilha do Marajó. Apenas metade dessas terras pertencia ao capitão Antonio, correspondendo à outra metade restante aos seus irmãos, José dos Passos e Marcello Gomes Corrêa de Miranda (Inventário Antonio Gomes Corrêa de Miranda, 1871). Eles também eram sócios de uma firma de criação de gado existente naquelas fazendas, administradas por Antônio desde 1858 (Diário do Comercio, 07.02.1859:04).

A reagregação da fazenda e a consolidação da sociedade foi resolvida através do casamento de Maria de Nazareth com o irmão de seu pai, o já referido, José dos Passos. Com esse arranjo matrimonial endogâmico, envolvendo tio e sobrinha, as terras não apenas se reagrupariam, como também se manteriam exclusivamente no grupo de parentesco. O pai de Maria, Antonio, faleceu em 1871. Treze anos mais tarde, foi a vez de seu 
tio/marido, José, vir a falecer. É aí que ficamos sabendo que Maria estava separada de José há cerca de dez anos, ou seja, logo após a morte de seu pai ela e o tio separaram-se (Inventário José dos Passos Gomes Corrêa de Miranda, 1884).

Do casamento, Maria e José dos Passos tiveram uma filha que não vivia com a mãe, mas com uma tia pela linha paterna. Enquanto era vivo, e já separado, José dos Passos residia em Belém com uma mulher solteira, com quem teve outra filha. Nessa mesma época, Maria foi morar em um vilarejo no rio Guajará, vivendo em comum com Antonio Luiz de Azevedo, com quem também teve outro filho. Seu segundo marido era um pequeno proprietário de terras sem posses ou pertencimento a um clã familiar tradicional (Inventário Antonio Luiz de Azevedo, 1888).

Com o fim do casamento de primeiras núpcias, Maria ficou sem nenhum bem da família ascendente. Somente após o falecimento de José dos Passos ela herdou três pequenas casas localizadas em Belém, não tendo obtido qualquer parte nas fazendas e no gado existente na ilha do Marajó. Mesmo que se leve em conta que não era incomum as filhas de proprietários de terra herdarem apenas bens móveis e jóias, enquanto os filhos ficavam com as terras e o gado em seus quinhões, Maria não tinha irmãos, apenas uma irmã, o que poderia tornar mais viável a agregação das terras em sua herança, haja vista a ausência de um herdeiro masculino, o que não ocorreu. ${ }^{2}$

Ao separar-se do irmão de seu pai, rompendo a aliança matrimonial estabelecida no universo da rede de parentesco e, ainda, casando-se com um indivíduo sem posses, Maria não teve

2 Dentre os inventários encontrados para Belém, neste período, mesmo havendo alguns que mantiveram um padrão de herança diferenciado para herdeiros masculinos e femininos, na maior parte deles, entretanto, o que se verificou foi a distribuição eqüitativa no tipo de bem deixado aos herdeiros. Contudo, as assimetrias de gênero foram encontradas quando as mulheres herdeiras eram solteiras, ficando, em geral, sem fazendas e gado, enquanto que, dentre as casadas, era corriqueiro o recebimento desses bens, o que não ocorreu com Maria (Cancela, 2006). 
direito à maior parte dos bens familiares. Some-se a isso, o fato dela não ter criado a filha, não se sabe se por opção ou imposição familiar. De qualquer forma, a menina ficou com a parentela, permanecendo, dessa forma, integrada à rede familiar ascendente, embora a mãe pareça ter sido alijada dessa rede, tendo em vista o fato de não ter recebido grande parte de sua herança, em especial os bens ligados à terra $e$ ao gado.

Essa história aponta para as tensões vividas pelas famílias na organização das alianças matrimoniais que, nem sempre, conseguiam dar conta das contingências patrimoniais e das inclinações individuais de seus membros, ocasionando rompimentos, formação de novas alianças e, neste caso, o viver em comum de uma jovem de elite com um homem pobre.

As trajetórias conjugais de Maria são importantes para não esquecermos que, mesmo se as pessoas dos grupos de elite encontram-se mais facilmente próximas à vivência e aos preceitos legitimados socialmente, pelas suas condições materiais $e$ valores, isso não implica que esses preceitos serão vividos $e$ acionados homogeneamente pelos indivíduos que compõem esses grupos. $\mathrm{O}$ mesmo vale para indivíduos de outros segmentos sociais.

Porquanto, ao analisar as práticas amorosas estabelecidas pela população mais pobre podemos ver a forma como os valores e comportamentos legitimados pela cultura estarão presentes nesses segmentos, sendo por eles assimilados, readaptados $e$, muitas vezes, questionados, num jogo de resistência e diálogo. Mais uma vez, a multiplicidade de comportamentos e práticas deve ser buscada, a fim de não serem criadas imagens unissonantes. Se as condições materiais encerram limites à experiência, delineando particularidades ao conjunto desses segmentos populares, as opções e escolhas individuais se fazem, do mesmo modo, presentes no cotidiano, trazendo à tona uma diversidade muitas vezes incômoda, mas que não pode ser velada. 
Destino cor-de-rosa, tensão e escolhas

\section{A trajetória de Jordolina}

Uma das formas de chegarmos ao universo das práticas amorosas dos indivíduos desse segmento é através dos processos civis e criminais. ${ }^{3}$ A partir deles fica clara a existência recorrente de casais vivendo junto, em situações de concubinato. Muitas vezes, o que chama a atenção nestas uniões é a circularidade que as circunscreve, pautando-as em uma convivência que rapidamente poderia ser rompida e uma nova união iniciada. Um relacionamento assinalado pela coabitação e a manutenção de relações sexuais poderia terminar e tão logo ser seguido por outro.

Essa situação pode ser encontrada na trajetória de vida e de amores da cearense Jordolina Maria da Conceição, de 20 anos, casada, serviços domésticos, moradora à estrada de São João, não sabendo ler nem escrever. Chamada a depor após a briga do português Francisco Ayres, 33 anos, carroceiro, morador à travessa Dona Januária, e Luis Costa, que resultou na morte deste último, Jordolina, ao mesmo tempo em que narra o motivo do conflito, conta um pouco de suas histórias amorosas e de seus deslocamentos:

que tendo sido abandonada por seu marido, com quem vivia em um sítio no rio Guamá, há cerca de quatro annos, veio para esta capital, onde tem residido até agora, que ha cerca de um anno freqüentou a sua casa e com ella teve relações amorosas durante quatro mezes um individuo de nome Luis Ribeiro da Costa, relações que cessaram em março do presente anno pouco mais ou menos; que depois fez o conhecimento de Francisco Ayres e com elle entreteu relações amorosas, vindo para esse fim ao quarto que num cortiço situado a estrada São João occupava o mesmo Ayres (Processos crimes, 1895).

3 Foram consultados 30 (trinta) processos de homicídio, lesão corporal, ofensa, atentado à honra e termos de bom viver, do $1^{\circ}, 2^{\circ}, 3^{\circ}$ e $4^{\circ}$ distritos de Belém, localizados no Arquivo do Tribunal de Justiça do Estado do Pará. 
Com seu depoimento, fragmentos de sua história de vida, que se confunde com as uniões amorosas encadeadas, passam a ser conhecidos. Com ainda 20 anos de idade, a migrante cearense Jordolina vinha de um sítio do interior do estado do Pará, localizado no rio Guamá, devendo viver de algum tipo de atividade de plantação e criação. Sua situação era bastante próxima de outros migrantes que, primeiramente, enveredavam pelas atividades ligadas à lavoura, em colônias agrícolas, vilas ou cidades interioranas $e$, posteriormente, deslocavam-se para a capital paraense em busca de novas oportunidades. No caso de Jordolina, o abandono do marido teria sido a causa do deslocamento para Belém, o que ocorrera há quatro anos, tendo à época, portanto, apenas 16 anos de idade.

Em Belém, ela vivia de serviços domésticos e morava em uma casa. Após dois anos na cidade, conheceu Luis, que passara a freqüentar sua casa e com quem teve relações amorosas durante o ano de 1894. O relacionamento chegou ao fim em março de 1895. Neste mesmo ano, Jordolina conheceu o português Francisco Ayres, com quem passou a viver, indo morar em sua casa, deixando assim de residir em seu antigo domicílio.

Nessa trajetória, percebe-se como a jovem de 20 anos, em menos de cinco anos, tivera três relacionamentos amorosos, sendo pelo menos dois deles com base em união consensual com coabitação em diferentes residências. $\mathrm{O}$ primeiro com o marido no interior do Estado, e os demais, já na capital, com Luis e Francisco.

Nem sempre é possível percorrer a trajetória das uniões desses casais, como pôde ser feito com a cearense Jordolina. No entanto, por vezes, é possível recuperar algum indício a partir da narrativa dos depoentes. É assim que uma testemunha, ao comentar o motivo da disputa envolvendo Manoel Gomes Pontes, cabo, de 48 anos, viúvo, paraibano, não sabendo ler nem escrever, e João Ferreira declara: 
Destino cor-de-rosa, tensão e escolhas

que não pode affirmar o que determinou este barulho, mas é voz pública que foi por cauza de uma mulher que sendo amante de Pontes sahio deste e foi amaziarsse com João Arsênio (Processos crimes, 1890).

O depoimento da testemunha deixa claro o fato de que estamos tratando, no que se refere à informalidade com a qual os casais dos segmentos populares podiam terminar e reafirmar uma nova união envolvendo relacionamento sexual e coabitação. Com isso, não se quer dizer que esta é uma característica desses relacionamentos, pois, mais à frente, vamos mostrar o universo de uniões mais estáveis também vividas por esses casais. Entretanto, em meio aos populares, não é incomum encontrar o arranjo e o término de relações amorosas e sexuais sem a formalização de um pedido de casamento, uma cerimônia oficial, um processo de divórcio ou uma partilha de bens.

O escasso patrimônio acumulado ajuda a compreender as raras situações encontradas envolvendo a partilha dos bens de um casal após o fim de uma união. Em relação a esse fato é interessante observar o auto envolvendo a parda Carlota Maria Eufemia - 25 anos, paraense, liberta, com uma filha e moradora à rua dos Martyres -, que fora amante de João Manuel da Cruz, cidadão brasileiro, com quem não mais vivia. Num dia em que João ausentou-se da cidade, Carlota foi até sua casa e, segundo ele: "quebrou objetos, conduziu outros, inclusive galinhas" (Autos de bem viver, 1880). Ela confirma parte do depoimento do examásio, mas adverte que só levou as galinhas porque pertenciam a sua filha. Aparentemente, ao sair da casa de João e do relacionamento que mantinham, Carlota não pôde levar suas coisas, voltando posteriormente, às escondidas, para buscar aquilo que acreditava ser de seu direito.

Vê-se, assim, de que forma o relacionamento dos dois amásios terminara, implicando na neo-residência de Carlota com a filha (que não se sabe se é de João), e a maneira informal pela 
qual uma das partes procurou recuperar o que acreditava ser seu patrimônio ao fim de um relacionamento - no caso, seis galinhas.

Nas situações apresentadas, as uniões estabeleciam-se sem maiores formalidades e os rompimentos implicavam no fim da coabitação, sendo necessário o amásio simplesmente levar suas coisas do quarto, da estância ou da pequena casa em que moravam. Pouco se fala nos processos e autos criminais de bens comuns de um casal, compreensível em meio a pessoas de poucos recursos e com pouco a partilhar.

As trajetórias desses indivíduos dão conta da flexibilidade com que podiam ser vividos e rompidos os relacionamentos amorosos em meio aos segmentos populares. Entre os motivos que ajudam a pensar a presença dessa prática no universo desses casais, podemos amealhar as adversidades e limites materiais vividos por esses grupos; a ausência ou inexpressividade de bens patrimoniais; a instabilidade do trabalho e da moradia; a maior autonomia da mulher pobre e trabalhadora em relação aos homens, permitindo-lhe a auto-sustentação e, com isso, uma suposta independência e dificuldade de o homem manter seu papel socialmente constituído de provedor. Finalmente, se a informalidade que poderia pontuar o início e o fim de uma união consensual não fazia parte das referências ideais de um comportamento legítimo, tampouco era motivo de expurgo $e$ afastamento total. De certa forma, as uniões consensuais constituíam-se em uma prática com a qual esses segmentos conviviam com freqüência e, se não faziam parte de seus valores modelares, também não deixavam de estar presentes em suas referências culturais.

O "viver junto", coabitando e mantendo relações sexuais, tornava-se, assim, uma realidade para os populares e o rompimento podia advir sem maiores formalidades, o que não significa que essas práticas eram aceitas de forma homogênea, ou mesmo, sem reservas. 
Destino cor-de-rosa, tensão e escolhas

\section{Em busca do matrimônio}

A propósito do caráter menos duradouro e circular das uniões vividas por alguns desses casais, foi possível encontrar relações duradouras. No registro de casamento religioso do cearense José Vicente Chavez, 40 anos, e da também cearense Maria Alves da Rocha, 37 anos, constava o fato de que eles, ao buscarem o matrimônio, já se encontravam casados no civil há 17 anos. Tendo vivido juntos por todo esse tempo, ao longo do qual tiveram três filhos, José e Maria resolveram casar-se na Igreja, renovando seus votos (Registro de casamento de José Chavez e Maria Rocha, 08.03.1910). Com três filhos e após estarem juntos há 13 anos, o português José Climateia Junior, 34 anos, e a pernambucana Beatriz Miranda, 31 anos, resolveram realizar o consórcio religioso (Registro de casamento de José Climatéia Junior e Beatriz Miranda, 18.02.1910). O mesmo ocorrendo com os paraenses Severino Monteiro, 32 anos, e Margarida Monteiro, 27 anos, contratados no civil e com quatro filhos, buscando o matrimônio após 12 anos de casamento (Registro de casamento de Severino Monteiro e Margarida Monteiro, 02.03.1910).

Esses casais viviam em uniões estáveis e legítimas do ponto de vista da autoridade secular, estando, no entanto, amancebados aos olhos da Igreja. Após longo tempo vivendo nessa situação, alguns já com vários filhos, outros em idades bem avançadas, procuravam reafirmar sua união matrimonial, recebendo o sacramento religioso.

Havia, ainda, casais que viviam em uniões estáveis, porém ilegítimas, que também procuraram as bênçãos da Igreja após longo período de convivência, como a do paraense de Abaetetuba, João Marcellino Ferreira, 35 anos, e Maria de Souza, 32 anos, nascida na Villa do Pinheiro, onde esta continuou a morar após passar a viver com João, com o qual teve quatro filhos. Depois de 11 anos vivendo juntos, eles realizaram o enlace matrimonial na Igreja de Nazaré (Registro de casamento de João Marcellino Ferreira e Maria de Souza, 12.04.1920). 
No caso seguinte, Raimundo do Espírito Santo, 40 anos, e Maria Justina, 35 anos, maranhense, também eram residentes na mesma Villa do Pinheiro, onde moravam amasiados há 12 anos (Registro de casamento de Raimundo do espírito Santo e Maria Justina, 20.04.1920). Em 1920, eles realizaram a cerimônia de casamento. E, por fim, Raimundo da Silva, 38 anos, e Thereza de Jesus, 40 anos, de quem não se sabe a naturalidade, viviam amasiados há 21 anos, quando, em 1920, casaram-se em Nazaré (Registro de casamento de Raimundo da Silva e Thereza de Jesus, 21.10.1920).

Os registros que revelam situações de casais vivendo uniões legitimadas pelo Estado ou uniões consensuais e que procuraram, em algum momento de suas vidas, unirem-se matrimonialmente, poderiam ser multiplicados. No entanto, os casos aqui exemplificados já demonstram a conjugalidade duradoura desses casamentos em meio à população formada por pessoas de diferentes gerações e naturais do interior e da capital do Estado, migrantes nacionais e estrangeiros. A geração, o tempo de convivência e a presença ou não de filhos não eram obstáculos para reafirmar o casamento, buscando legitimá-lo frente à Igreja.

Mesmo que boa parcela da população vivesse em meio a uniões ilegítimas, o matrimônio era uma referência importante na representação social, e a busca pela legitimidade circulava entre os casais dos segmentos populares, embora, para estes últimos, as dificuldades materiais, a ausência de patrimônio e o costume, além de outros fatores enunciados anteriormente, tornassem menos corriqueiros os consórcios institucionalizados. Contudo, nem por isso, o casamento deixava de ser um valor, conferindolhes um status diferenciado e tornando-se, para muitos, um ideal a ser alcançado, mesmo após longo tempo de convivência estável com filhos crescidos. 
Destino cor-de-rosa, tensão e escolhas

\section{A longa familiaridade}

Muitas vezes, a amizade e o conhecimento prolongado que os casais mantinham eram objeto de preocupação por parte dos parentes que procuravam rapidamente legitimar a união.

A longa familiaridade constituía-se em uma das premissas aceitas pela Igreja Católica para conferir dispensas de impedimentos canônicos aos contraentes. ${ }^{4}$ Em vários pedidos à Arquidiocese de Belém podia-se encontrar como um dos argumentos para a obtenção da solicitação de dispensa de documentação para casamento "a longa familiaridade que ha entre elles que muito pode prejudicar a reputação da oradora". ${ }^{5}$ No termo de dispensa para contrair matrimônio feito por Pedro de Alcântara Ramos da Silva e Joaquina Carolina da Costa e Silva, paraenses, filhos legítimos e moradores na freguesia da Sé, o pedido é feito em função do impedimento de $2^{\circ}$ grau de consangüinidade existente entre eles porque a "mãe do orador é irmã da mãe da oradora". Mas, para que a dispensa fosse concedida, argumentou-se em torno da longa familiaridade existente entre os noivos, acrescentando-se o fato da nubente ser órfã e de Pedro tê-la retirado da casa materna. A regularidade e a proximidade da convivência agravada com a coabitação entre os noivos poderiam facilitar e estimular os encontros amorosos e o

\footnotetext{
4 Essas dispensas eram solicitadas pelas famílias do interior do Estado e da capital para seus párocos locais que, por sua vez, encaminhavam-nas ao arcebispado da Sé para serem julgadas. Entre os casos de dispensa solicitados predominavam aqueles relativos à existência de parentesco por afinidade e consangüinidade; pedidos de liberação dos proclamas, das certidões de batismo e óbito (este último, em caso de viuvez do nubente que buscava novamente o matrimônio). Todos esses documentos foram consultados no AAB.

5 Solicitação de dispensa para contrair matrimônio que fazem Pedro de Alcântara Ramos da Silva e D. Joaquina Carolina da Costa e Silva. Paróquia da Sé. Belém, 11.01.1875. Caixa: 1800. AAB. "Orador" e "oradora" são os termos usados para denominar os nubentes na documentação relativa à obtenção de dispensa de impedimentos para contrair matrimônio.
} 
envolvimento sexual, sendo, portanto, motivo para acelerar o recebimento do sacramento religioso.

Por vezes, o controle em torno dos relacionamentos amorosos e as tentativas de vigilância esbarravam na flexibilidade com que muitos dos casais dos segmentos populares viviam seus namoros. A convivência e a proximidade de moradia ou mesmo a coabitação $e$ as relações sexuais estabelecidas faziam parte da prática do namoro de muitos desses casais. Foi assim com o envolvimento de Joaquim Gomes de Carvalho, 22 anos, paraense, foguista, e Virgilina Maria da Trindade, também paraense de 22 anos. As famílias se conheciam desde que eles eram pequenos e os dois sempre mantiveram contato. Da amizade surgiu o namoro e com ele o intercurso sexual. Eles solicitaram a dispensa dos proclamas que deveriam correr nas quatro paróquias durante três domingos em razão da noiva estar "infamada" $e$, portanto, desejarem "reparar essa falta grave quanto antes" (Solicitação de dispensa para contrair matrimônio que fazem Joaquim Gomes de Carvalho e Virgilina Maria da Trindade, 16.04.1898).

Havia situações em que, por motivo de parentesco e/ou laços de afinidade, o casal vivia na mesma casa e, a partir da convivência cotidiana, iniciava uma relação de amizade e namoro. Isso ocorreu com Domingos dos Santos Paes, 32 anos, cearense e viúvo da irmã de Benedicta Cardoso de Souza, 15 anos, também cearense e moradora na rua Antonio Barreto, freguesia de Nazaré. Por ter sido casado com sua irmã, Domingos e Benedicta moravam na mesma casa e passaram a entreter uma amizade, daí a preocupação dos pais da nubente em acelerar o matrimônio, dada

a familiaridade intima entre os oradores, sob o mesmo teto na casa paterna da oradora: perigo de infâmia não effectuando o cazamento; que são pobres e que não podem satisfazer os custos (Solicitação de dispensa para contrair matrimônio que fazem Domingos dos Santos Paes e Benedicta Cardoso de Sousa, 28.09.1902). 
Em algumas situações, o fato de recorrer-se ao perigo de infâmia da noiva poderia ser um artifício usado pelo casal $e$ pela família dos noivos para facilitar a concessão das dispensas por parte da Igreja Católica. Da mesma forma, a alegação de que o casal havia tido cópula carnal poderia também ser usado como argumento para apressar o casamento. Dessa forma, o pároco local deveria atestar a situação dos nubentes, seja por conhecimento próprio, seja pelo depoimento de testemunhas, em geral, familiares dos consortes. Cabia à autoridade eclesiástica local confirmar se realmente havia a possibilidade de prejuízo à reputação da oradora, se havia tido incesto entre o casal, se eles eram ou não pobres para arcar com as despesas da dispensa e o quanto podiam contribuir com a caixa pia [explicar em nota caixa pia].

Atentos a esse expediente e para que não houvesse dúvidas, alguns párocos indicavam em suas declarações que o casal havia tido cópula carnal sem a intenção de pressionar as autoridades para a obtenção da dispensa. Em um dos pedidos vindos do interior do Estado para análise na capital, o pároco observara que: "os oradores por fragilidade humana mas sem anuir de facilitar a dispensa, se conheceram carnalmente" (Solicitação de dispensa para contrair matrimônio que fazem Aprígio Ribeiro Pinto e Firmina Joanna da Luz, 28.04.1875; grifos meus).

Menos do que buscar a maior ou menor presença dessa ou daquela forma de união dos casais dos segmentos populares, é importante destacar a diversidade de modelos e de práticas dos grupos sociais. Os limites e condições da vida material, a circularidade nos espaços públicos, a fluidez da casa e da rua, a ausência de patrimônio, a convivência permitida e cotidiana com uniões não legítimas, a maior autonomia das mulheres pobres, possíveis entraves e custos na realização do casamento, são questões que ajudam a compreender a recorrência das uniões consensuais. Mas, a propósito dessas dificuldades, outras escolhas e opções também se mostraram viáveis e foram experenciadas por essa população. Se o casamento formal não era uma prática 
corriqueira, isso não implica que ele não estava presente nesses segmentos e que, de alguma forma, fizesse parte de seus ideais $e$ valores, servindo como referência.

Como dissemos, não se trata de buscar aqui a proporcionalidade de uma ou de outra forma de casamento, institucionalizado ou não. O que importa é dar conta das inúmeras estratégias usadas por essas pessoas para estabelecer suas relações de conjugalidade e as representações a elas atribuídas.

\section{Educação, matrimônio e parentalidade}

Nessa rede intricada e nada linear de significados e práticas que o casamento pode assumir é possível compreender a história da jovem Ambrosina Monteiro Franco. Aos 19 anos, ela ainda era considerada de menoridade e, portanto, subordinada ao poder paterno. Todavia, Ambrosina era bacharel em "sciencias e letras pelo Gynasio Paes de Carvalho" e atuava como professora normalista. Com base nessa formação, ela deu entrada em um requerimento de "supprimento paterno para fins de casamento". Através desse documento, a normalista pretendia adquirir sua emancipação. O propósito de tal atitude estava relacionado ao fato do pai de Ambrosina, Jeronymo Aquino do Rego Franco, não consentir no casamento da filha com o marido que ela escolhera. O eleito era empregado federal e, dessa forma, teria como sustentar uma família, não sendo um qualquer, o que reforçava os argumentos da suplicante.

Após a morte de sua genitora, Ambrosina passara a viver na casa de Angelina Para-Assú da Serra Freire, que a criou e cuidou de sua educação. Esta senhora era casada e não possuía muitas posses, mas tinha o suficiente para que Ambrosina se formasse. ${ }^{6}$ Em 1914, com o falecimento de sua tutora, a normalista passou a

6 Angelina era casada com Edgard Nelson da Serra Freire, o qual, três anos após o seu falecimento, volta a casar-se abrindo, para tanto, um auto de negação de bens, onde garantia a ausência de bens (Auto de negação de bens, 11.05.1917). 
Destino cor-de-rosa, tensão e escolhas

viver em casa de uma provável parente de Angelina, Cesaria Godóes da Serra Freire, de onde seu pai pretendia tirá-la.

Entre os argumentos utilizados pelo advogado da menor, Américo Lins de Vasconcellos Chaves, para garantir sua emancipação, estava o fato de que:

...o pátrio poder que seo pae Jeronymo Aquino do Rego Franco exercia sobre sua pessoa e bens terminou não obstante a supplicante ainda não ter atingido a maioridade, por acontecimentos que operam em direito, a emancipação legal dos filhos famílias (Auto de requerimento de supprimento paterno para casamento, 28.03.1914).

Baseando-se nos ensinamentos de Clóvis Bevilaqua, entre esses acontecimentos legais, destaca-se o fato da jovem ter-se bacharelado em letras e recebido o grau de professora normalista, tendo, portanto, uma formação educacional e profissional. Ainda segundo o advogado: "Esses diplomas são scientíficos e como taes operam a emancipação legal" (Id. ib.).

O processo é julgado procedente ainda em 1914, e Ambrosina torna-se emancipada para todos os atos da vida civil, sem restrição alguma, de acordo com o despacho do juiz, Francisco Severino.

Nesse processo, chama atenção o fato da normalista questionar uma certa ordem baseada no pátrio poder sobre os filhos menores e, ainda, sobre o direito paterno de escolha ou rejeição de um cônjuge. Esse fato demonstra a tendência, verificada no século XIX, dos jovens cada vez mais ficarem independentes da rede familiar para a realização de alianças matrimoniais em função de sua formação educacional $e$ profissional, que lhes possibilitava a manutenção de uma família com recursos de seu próprio trabalho. Nessa perspectiva, a situação vivida por Ambrosina é ainda mais exemplar por se tratar de uma mulher que reclama o direito de escolha do parceiro, tendo como argumento sua formação escolar e profissional. No entanto, se de um lado ela questionava uma norma, de outro, ela 
o fazia na tentativa de realizar uma prática normativa representada pelo casamento formal.

Ao questionar o poder paterno de escolher seu marido, Ambrosina buscava não o rompimento de uma norma, mas a consolidação de uma prática normativa, utilizando meios pouco convencionais. Esse caso aponta para a complexidade de práticas e representações que poderiam envolver o casamento a partir da trajetória de uma jovem normalista de camada média como Ambrosina, situações que mostram a imbricada trama da experiência e as possibilidades de leitura que a vivência encerra.

\section{De noivado, bonds e balas}

Nesse período, em Belém, em meio às famílias da elite, era possível encontrar nos jornais notas anunciando os esponsais. A publicidade do noivado, assim como do casamento, fazia parte das distinções de fato dessas famílias, conferindo-lhes prestígio $e$ status. Todavia, esta prática não era comum em meio às camadas pobres de Belém. Poucas vezes víamos discriminada a condição de noivos dos casais.

Uma das situações de noivado merece ser destacada, pois, embora o casal envolvido possuísse alguma posse, afinal, a noiva era professora e o noivo empregado no comércio, as famílias não eram tradicionais na cidade, tampouco possuíam grandes somas de recurso - o noivo pertencia a uma família pobre de migrantes cearenses, tendo tido alguma ascensão profissional.

Indo para o trabalho, Pedro Avellino de Aragão, 42 anos, conheceu Georgette Pinet, paraense, branca, 23 anos, professora normalista. Ficamos sabendo da existência deste casal através de um processo crime aberto por tentativa de assassinato cometida por Georgette contra Aragão, como Pedro era mais conhecido.

Eles se conheceram em um bond à Estrada de Ferro de Brangança, onde Aragão circulava para ir ao trabalho e Georgette para visitar a mãe que se encontrava doente na Vila do Pinheiro, localidade próxima à Belém. Ele a teria a abordado no trem: 
Destino cor-de-rosa, tensão e escolhas

na occasião em que a respondente descia na Estação do Entroncamento procurando-lhe tolher-lhe a passagem voltou-se para a respondente proferindo as seguintes palavras: "Minha senhora eu estou loucamente apaixonado por V. Exa" (Processos crimes, 1917).

Isso teria se passado em um domingo à tarde e, logo na quinta-feira, eles voltariam a encontrar-se mais uma vez na estação. Nessa ocasião, eles conversaram e Aragão ofereceu a Georgette um cartão de visitas, dizendo-se apaixonado e que

era um homem honrado, tendo família composta de irmãs $e$ irmãos $e$ que a respondente e seus pais poderiam ficar descansados, porque sendo elle bom filho e bom irmão, seria bom marido. ${ }^{7}$

Na semana seguinte, Aragão foi à casa de Georgette onde se encontrou com o pai dela e, durante o almoço, falou de seu propósito de casamento, vindo a ficar noivo após o pedido feito por um amigo, Benigio Filgueiras. O noivado dos dois foi noticiado no Jornal Folha do Norte, na seção "Notas Mundanas":

$\mathrm{O}$ dr. Benigio Filgueiras pediu ante-hontem em casamento para o capitão Pedro Arcellino Aragão, empregado da marchantaria dos snrs. Guilherme Feio \& cia, a prendada senhorinha Maria Geogette Pinet, filha do industrial sr. Emilio Pinet e sua esposa d. Joanna Alves da Costa Pinet. O pedido foi acceito com satisfação pela família da noiva (Folha do Norte, 8.05.1917:02).

Vê-se, portanto, que houve um pedido e a publicidade do noivado entre as partes, formalizando a situação do casal frente à sociedade. Embora a nota indique que Pedro Aragão era capitão, esse dado não aparece em momento algum do processo, sendo

7 Depoimento de Georgete Pinet. Processo crime. $4^{\circ}$ vara. Homicídio. Caixa: 1917-1918. Ano: 1917. ATJEPA. 
feita apenas referência a sua condição de empregado do comércio. A propósito do emprego, Aragão sustentava a casa onde moravam a mãe e as irmãs. Como dissemos, a família era de origem humilde e composta de migrantes cearenses, alguns deles pobres e de condição modesta. Segundo o depoimento de Aragão, este foi justamente um dos motivos que teriam levado ao desentendimento com Georgette, segundo ele:

[ela] começou a fazer algumas observações indevidas ao respondente; que extranhou ter o respondente alguns irmãos pobres vivendo uma vida modesta; que depois destas observações Georgette perguntou ao respondente quem pagava a despeza feita em casa do mesmo para tanta gente comer; que o respondente declarou que era elle próprio que fazia de bom grado aquella despeza, tendo dito Georgette que quando ella se cazasse o respondente não faria mais sozinho tanta despeza, pois caso os parentes do respondente quizessem ter refeições em sua casa, teriam que pagar uma mensalidade. ${ }^{8}$

A família de Georgette tinha algum recurso, embora não fosse rica, mesmo tendo seu pai sido citado na nota de jornal como industrial. Eles moravam em uma área afastada da cidade e não pertenciam às famílias tradicionais da sociedade local.

Após o pedido de noivado e o estreitamento da relação entre as famílias, Georgette afirma que passou a freqüentar a casa da mãe e das irmãs do noivo, onde iriam morar depois de casados, pois Aragão não tinha pretensão de estabelecer novo domicílio, devendo continuar sustentando sua família. Da mesma forma, Georgette veio a saber que Aragão tivera um filho com uma moça a qual deflorara e que o menino era criado por sua família e continuaria a morar com eles após o casamento.

Pouco menos de dois meses depois de se conhecerem $e$ ficarem noivos, Aragão ficou alguns dias sem aparecer na casa da

8 Depoimento de Pedro Aragão (Processos crimes, 1917). 
Destino cor-de-rosa, tensão e escolhas

noiva até mandar dizer, através de um cunhado, que "por incompatibilidade de gênios" não mais desejava casar-se. Reagindo ao comunicado, Georgette foi comprar uma arma no comércio e dirigindo-se à mesma Estação de São Brás, onde havia conhecido Aragão, esperou-o e nele atirou sem causar-lhe ferimento.

$\mathrm{Na}$ versão dela, apresentada em depoimento à polícia, o rompimento do noivado estaria associado ao fato de que:

Depois do noivado, Aragão entrou a fazer exigências a respondente que iam de encontro aos princípios que esta recebera de seus pais e ao mesmo tempo offendiam o seu pudor de moça honesta, bem como pedir-lhe beijos $e$ outras carícias incompatíveis com sua posição de homem honrado que se dizia ser. ${ }^{9}$

Para Aragão, o fim do noivado devia-se ao fato da respondente não aceitar que ele sustentasse sua família, porquanto,

como bom filho $e$ amigo de sua família sentiu-se logo doente ouvindo as censuras de Georgette, tendo dito na volta a sua irmã Roza que ia acabar o seu noivado por quanto Georgette, com o seu gênio e o seu modo de ser, vinha trazer a desunião da família do respondente. ${ }^{10}$

Percebemos como, tanto na alegação de Georgette quanto na de Aragão, as defesas são feitas em função da honra dos indivíduos e da família. Fatores como amizade, união, honestidade e virgindade também foram acionados para legitimar a imagem dos envolvidos frente às autoridades. Não é o propósito deste trabalho discutir as questões referentes à necessidade de construção de tais imagens como recurso jurídico utilizado pelos

9 Depoimento Geogette Pinet (Processos crimes, 1917).

${ }^{10} \mathrm{Id}$. ib. 
envolvidos e seus advogados, nem a forma pela qual a justiça interpreta essas alegações (Corrêa,1983; Borelli, 1989). O que propriamente importa aqui é destacar de que forma se estabeleceu o noivado e como ele foi vivenciado entre o casal. Em relação ao estabelecimento, vale ressaltar que o pedido foi feito por uma terceira pessoa, amigo do noivo, à família da noiva para conferirlhe maior confiabilidade. Da mesma forma, o namoro só pôde ter início após o pedido de noivado e, a partir daí, os encontros aconteciam nas residências das famílias do casal.

No entanto, em menos de dois meses, segundo os argumentos apresentados por Aragão, as diferenças sociais existentes em meio a sua família e o fato dele sustentá-la teriam incomodado Georgette, gerando o fim do noivado; para ela, a plasticidade com que Aragão queria viver o noivado, exigindo-lhe carícias e prova de honestidade, o levaram ao término. A propósito da formalidade do pedido, cabendo até mesmo uma nota no jornal da capital, o fim da relação se deu de maneira informal, com o cunhado de Aragão indo comunicar a Georgette o término do compromisso.

É possível que, para Aragão, o significado da condição de noivado não fosse tão rígido, não havendo alianças familiares a serem consolidadas a partir da união do casal, tampouco negócios, acordos financeiros, empréstimos ou outras obrigações que tornassem o desfecho do contrato matrimonial mais complicado. Uma simples comunicação encerrava o compromisso assumido, supostamente não interferindo na vida e no trabalho de Aragão ou de Georgette e seu pai. Entretanto, as questões relativas à honra, fosse de mulher honesta ou de bom filho, foram os argumentos usados para questionar ou justificar o fim do futuro enlace.

O caso é julgado procedente e, em novembro de 1917, Georgette é considerada culpada. Ela é encaminhada para tratamento no hospital da Ordem Terceira, pois estaria doente, além do que seu advogado alega que a cadeia pública era imprópria "para nella ser recolhida uma moça virgem e de família 
honesta". Quase quatro anos depois, em novo recurso, o tribunal absolve a ré em outubro de 1921.

Neste caso, é importante observar que, embora o casal pertencesse à camada média urbana, onde se supõe que o noivado possui certa importância social, houve informalidade no fim do compromisso. Isso sugere que, o fato de não haver muitas situações patrimoniais e obrigações mútuas de trabalho e negócios envolvidas nessa possível aliança matrimonial facilitava a pouca rigidez que marcara o término do compromisso. As ligações, embora passassem pelo conhecimento, autorização e necessidade de legitimação familiar, também ficavam à mercê das inclinações e vontades individuais, podendo mais facilmente serem rompidas quanto menos obrigações morais, patrimoniais e de negócios estivessem arroladas.

Todavia, para além das vicissitudes dos sentimentos, escolhas e opções individuais, os valores familiares e as questões de honra, compromisso e casamento que perpassavam os vários segmentos sociais, estavam presentes culturalmente e, levando-os em conta, essas pessoas falaram em nome da defesa da sua própria honra de mulher honesta e de sua família, como declarou Georgette, e para manter a união de seu grupo familiar, como argumentou Aragão.

Para além de uma regra e uma prática tida como legítima, múltiplos foram os modelos e comportamentos atualizados pelas pessoas de distintos segmentos sociais na vivência de seus relacionamentos. Se o noivado e o casamento eram "cor-de-rosa" para muitas mulheres, como queria crer Miss felicidade, para tantas outras resultaram em tensão e conflito, mas tampouco pareciam ser feitos apenas de espinhos, ou mesmo, no caso do casamento, uma experiência distante da vida de mulheres pobres. 
Cristina Donza Cancela

\section{Referências bibliográficas}

Botelho, João José da Costa. A família Castro no Pará. Belém, Falangola, 1983.

BOURDIEU, Pierre. Condição de classe e posição de classe. In: AGUIAR, Neuma. Hierarquias em classes. Rio de Janeiro, Zahar, 1973.

CANCELA, Cristina Donza. Casamento e relações familiares na economia da borracha. Belém (1870-1920). Tese de Doutorado, História, Universidade de São Paulo, 2006.

CORRÊA, Mariza. Morte em família. Rio de Janeiro, Graal, 1983.

LEWIN, Linda. Política e parentela na Paraíba: um estudo de caso de oligarquia de base familiar. Rio de Janeiro, Record, 1993.

NAZZARI, Muriel. O desaparecimento do dote: mulheres, famílias e mudança social em São Paulo, Brasil, 1600-1900. São Paulo, Companhia das Letras, 2001.

PEDRO, Joana Maria. Mulheres faladas e mulheres honestas: uma questão de classe. Florianópolis, Editora da Universidade Federal de Santa Catarina (UFSC), 1998.

SAmArA, Eni de Mesquita. As mulheres, o poder e a família. São Paulo, Marco Zero/Secretaria de Estado da Cultura, 1989.

\section{Periódicos}

Folha do Norte, 8.05.1917.

Jornal Diário do Comercio, 07.02.1859.

Revista A Semana, v.03, n 107, 17.04.1920.

Revista A Semana, v.03, n 56, 12.09.1919.

Revista A Semana, v.03, n 110, 08.05.1918.

\section{Documentos}

Auto de negação de bens, 11.05.1917. Cartório Odon Rhossard ATJEPA.

Auto de requerimento de supprimento paterno para casamento, em que é requerente Ambrosina Monteiro Franco. Arquivo do Tribunal de Justiça do Estado, Cartório Odon Rhossard. 28.03.1914.

Autos de bem viver. $2^{\circ}$ distrito.Caixa: 1880-1885. Doc. 02. Ano: 1880. ATJEPA.

Inventário Antonio Luiz de Azevedo. Caixa: 1888, Ano 1888. ATJEPA. 
Destino cor-de-rosa, tensão e escolhas

Inventário José dos Passos Gomes Corrêa de Miranda. Caixa: 1884. Ano 1884. ATJEPA.

Inventário Antonio Gomes Corrêa de Miranda. Caixa: 1871. Ano 1871. ATJEPA.

Processos crimes. 4 vara. Homicídio. Caixa: 1917-1918. Ano: 1917. ATJEPA.

Processos crimes. $3^{\circ}$ Distrito Criminal. Homicídio. Caixa: 1895. Doc. 05. Ano: 1895.ATJEPA.

Processos crimes. $2^{\circ}$ Distrito Criminal. Homicídio. Caixa: 1890. Doc. 03. Ano: 1890.ATJEPA.

Registro de casamento de Raimundo da Silva e Thereza de Jesus. Paróquia de Nazaré. Data: 21.10.1920. Livro: n 17 (1918-1924). AAB

Registro de casamento de Raimundo do espírito Santo e Maria Justina. Paróquia de Nazaré. Data: 20.04.1920. Livro: no 17 (1918-1924). AAB

Registro de casamento de João Marcellino Ferreira e Maria de Souza. Paróquia de Nazaré. Data: 12.04.1920. Livro: nº 17 (1918-1924). AAB

Registro de casamento de José Chavez e Maria Rocha. Paróquia de Nazaré. Data: 08.03.1910. Livro: n 14 (1908-1911). AAB

Registro de casamento de Severino Monteiro e Margarida Monteiro. Paróquia de Nazaré. Data: 02.03.1910. Livro: no 14 (1908-1911). AAB

Registro de casamento de José Climatéia Junior e Beatriz Miranda. Paróquia de Nazaré. Data: 18.02.1910. Livro: no 14 (1908-1911). AAB

Solicitação de dispensa para contrair matrimônio que fazem Domingos dos Santos Paes e Benedicta Cardoso de Sousa. Paróquia da Sé. Belém, 28.09.1902. Caixa: 1800. AAB.

Solicitação de dispensa para contrair matrimônio que fazem Joaquim Gomes de Carvalho e Virgilina Maria da Trindade. Paróquia de Nossa Senhora de Nazareth. Belém, 16.04.1898. Caixa: 1800. AAB

Solicitação de dispensa para contrair matrimônio que fazem Aprígio Ribeiro Pinto e Firmina Joanna da Luz. Paróquia de Portel. Belém, 28.04.1875. Caixa: 1800. AAB.

Solicitação de dispensa para contrair matrimônio que fazem Pedro de Alcântara Ramos da Silva e D. Joaquina Carolina da Costa e Silva. Paróquia da Sé. Belém, 11.01.1875. Caixa: 1800. AAB. 